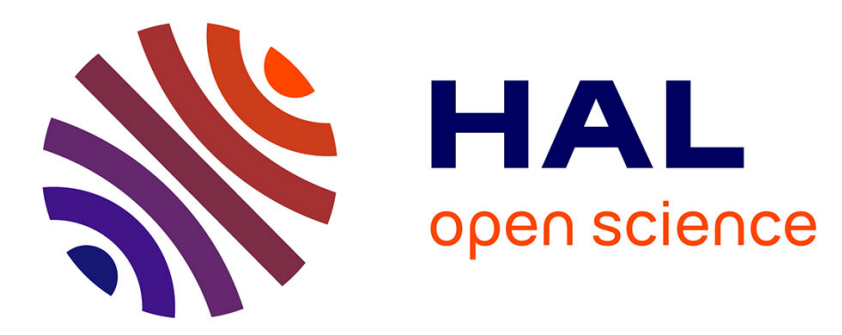

\title{
Effect of grain size distribution on Raman analyses and the consequences for in situ planetary missions
}

Frédéric Foucher, G. Lopes-Reyes, Nicolas Bost, F. Rull-Perez, P. Rüssmann, Francès Westall

\section{- To cite this version:}

Frédéric Foucher, G. Lopes-Reyes, Nicolas Bost, F. Rull-Perez, P. Rüssmann, et al.. Effect of grain size distribution on Raman analyses and the consequences for in situ planetary missions. Journal of Raman Spectroscopy, 2013, 44 (6), pp.916-925. 10.1002/jrs.4307 . insu-00819722

\section{HAL Id: insu-00819722}

\section{https://hal-insu.archives-ouvertes.fr/insu-00819722}

Submitted on 19 Aug 2013

HAL is a multi-disciplinary open access archive for the deposit and dissemination of scientific research documents, whether they are published or not. The documents may come from teaching and research institutions in France or abroad, or from public or private research centers.
L'archive ouverte pluridisciplinaire HAL, est destinée au dépôt et à la diffusion de documents scientifiques de niveau recherche, publiés ou non, émanant des établissements d'enseignement et de recherche français ou étrangers, des laboratoires publics ou privés. 


\title{
Full title
}

Effect of grain size distribution on Raman analyses and the consequences for in situ planetary missions

\section{Short title}

Effect of grain size distribution on Raman analyses

\section{Authors and affiliations}

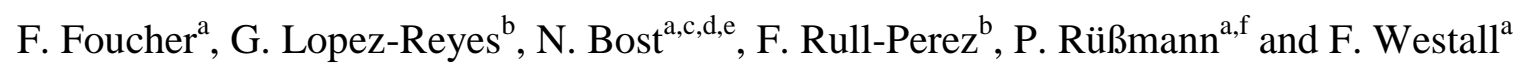

${ }^{a}$ Centre de Biophysique Moléculaire, UPR CNRS 4301, 45071 Orléans cedex 2, France,

${ }^{\mathrm{b}}$ Universidad de Valladolid, Unidad Asociada Universidad de Valladolid - CSIC - Centro de Astrobiologia (UVa-CAB), Valladolid, Spain.

${ }^{\mathrm{c}}$ Univ d'Orléans, ISTO, UMR 7327, 45071, Orléans, France

${ }^{\mathrm{d}}$ CNRS/ INSU, ISTO, UMR 7327, 45071 Orléans, France

${ }^{\text {e }}$ BRGM, ISTO, UMR 7327, BP 36009, 45060 Orléans, France

${ }^{\mathrm{f}}$ Université d'Orléans, Château de La Source, Avenue du Parc Floral, BP 6749, 45067

Orléans cedex 2, France

(frederic.foucher@cnrs-orleans.fr / Fax:+33-2-38631517)

\begin{abstract}
Raman spectroscopy can be used for analysing both mineral and organic phases, thus allowing characterisation of the microbial-scale geological context as well as the search for possible traces of life. This method is therefore very useful for in situ planetary exploration missions. Compared to the myriad of sample preparation techniques available in terrestrial laboratories, the possibilities for sample preparation during in situ missions on other planetary bodies is extremely limited and is generally restricted to abrasion of rock surfaces or crushing of the target samples. While certain techniques need samples to be prepared in powder form, such as X-Ray Diffraction, this kind of preparation is not particularly suitable for optical microscopy and/or Raman spectroscopy. In this contribution, we examine the effects of powdering rock and mineral samples on optical observations and Raman analyses. We used a commercial Raman spectrometer, as well as a Raman Laser Spectrometer (RLS) that simulates the instrument being developed for the future ExoMars 2018 mission. The
\end{abstract}


commercial Raman spectrometer documents significant modifications to the spectra of the powdered samples, including broadening of the peaks and shifts in their position, as well as the appearance of new peaks. These effects are caused by localised heating of the sample under the laser beam and amplification of nominal surface effects due to the increase in surface area in finer grain sizes. However, most changes observed in the Raman spectra using the RLS system are negligible because the relatively large (50 $\mu \mathrm{m}$ diameter) laser spot size produces lower irradiance. Furthermore, minor phases were more easily detectable in the powdered samples. Most importantly, however, this sample preparation method results in the loss of the textural features and context making identification of potential fossilized microbial remains more problematic.

Keywords: in situ Raman spectroscopy, powder, Mars, minerals, rock

\section{Introduction}

Raman spectroscopy can be used for analysing both inorganic (e.g. minerals) and organic molecules making it a particularly interesting technique for in situ planetary science exploration. This is particularly relevant because recent and future missions are focussing on astrobiological investigations searching for complex organic molecules and traces of life. Several studies have focussed on the development and calibration of Raman spectroscopy for science space applications. ${ }^{[1-7]}$ Irrespective of the rocky body explored, one of the primary goals of in situ missions is to understand the geological context of the landing sites and a Raman Laser Spectrometer (RLS) will be included as part of the Pasteur payload on the upcoming ExoMars rover mission (ESA/Roscosmos, 2018) whose goal is to search for evidence of microbial remains in the Martian soil. ${ }^{[8]}$

Weight, size and power limitations of spaceflight instrumentation means that the resolution and sensitivity of analyses made in situ are limited compared to those made in terrestrial laboratories. In the same way, only limited sample preparation can be undertaken in situ. In order to standardise the amount of material used for analysis by the mission instruments, samples are crushed into powders. Powdered preparations are the preferred method of sample preparation for techniques, such as X-Ray Diffraction (XRD) and gas chromatograph mass spectrometry (GC-MS). Subsurface material obtained from depths from 0.5 to 2 meters will be taken during the ExoMars mission and will be crushed for analysis by a suite of instruments on the rover, including the RLS. ${ }^{[9,10]}$ Note that some indication of the spatial context of different grains could be provided by the Close-Up Imager (CLUPI) instrument on board the ExoMars rover, prior to crush the drilled core material. ${ }^{[1]}$

Many rocks and targets for in situ planetary investigations occur naturally as granular materials with variable grain size distributions (e.g., sands, gravels, clays, etc.). Identification of the individual minerals within these samples using optical microscopy can sometimes be difficult, in particular for smaller grain sizes. Raman spectroscopy is particularly useful for such investigations as it can identify each individual mineral phase at the microscopic scale. 
However, in order to dissociate the individual spectra of each component, the grains must be larger than the analysed volume. ${ }^{[12,13]}$

Of specific interest for Martian missions is the search for life and the presence of organic matter in the rocks and soils of the red planet. Whether or not life emerged on Mars, organic molecules should be detected because carbonaceous meteorites and micrometeorites containing abiotic organic material reach the planet surface, even at the present day. ${ }^{[14]}$ Raman spectroscopy is capable of detecting carbonaceous matter in geological materials, whether of biological or abiological origin. Raman spectroscopy has been used to investigate abiogenic carbon in a variety of Martian meteorites ${ }^{[15]}$ as well as to characterize modern biological carbonaceous matter in rocks. ${ }^{[1,6]}$ Some studies have been able to detect biological carbon molecules (e.g. beta-carotene, amino acids, etc) using various test conditions including miniaturised and remote Raman spectrometers on powdered minerals and during in situ measurements. ${ }^{[6,16-19]}$ In these tests, organics were added to the samples prior to analysis in order to establish detection limits. In terrestrial materials, the presence of biogenic organic matter produces abundant fluorescence in granular rocks (e.g., clays ${ }^{[20]}$ ). Even in very ancient rocks (e.g. 3.5 billion years old) degraded biological carbon in the form of kerogen can be easily detected by Raman spectroscopy. Although it is not possible to demonstrate a biological origin of the kerogen in ancient rocks, Raman mapping of the organic component in its mineralogical context can be used to aid detection of biosignatures, for example in rocks $\sim 3.5$ Ga old. ${ }^{[21,22]}$

The Raman spectra from crystalline materials may be modified by different parameters and phenomena, as shown in Fig. 1. Since the crushing process can potentially influence all of these conditions, the Raman spectrum obtained from a powdered sample may in fact be quite different from that obtained from the (original) bulk sample. For example, changes in wavenumber and peak width in the Raman spectra of powdered quartz and olivine powders have previously been observed. ${ }^{[23]]}$ The aim of this study is therefore to determine whether any additional Raman spectral parameters change when powdered rocks and minerals are used and whether these changes impact the geological (and astrobiological) interpretations of the data obtained. This investigation is focussed particularly on analytical conditions during future extraterrestrial in situ missions. We first studied the effects of crushing on the Raman spectra of different minerals using a micro-Raman laboratory device. Raman mapping of several grain sizes was used to characterize the fine scale changes in the spectra. The RLS simulator was used to determine if the observed grain size effects could potentially hamper correct identification of minerals during the ExoMars mission. Additionally, the consequences of crushing on the analyses of igneous rocks and sedimentary rocks (the latter containing fossilised biosignatures) were examined. Finally, the advantages and disadvantages of using crushed rocks are discussed.

\section{Materials}




\section{Minerals}

The following minerals were selected to study the changes in spectra induced by crushing.

\section{Silicon}

Silicon is more an inorganic material than a mineral since it occurs very rarely in nature ${ }^{[24]}$ as small phases associated with gold. ${ }^{[24,25]}$ Thus, although not a representative Martian mineral, silicon was used as a control because it has a diamond structure $\left(\mathrm{O}^{7}{ }_{\mathrm{h}}\right)$ and therefore only one first-order Raman-active Si-Si stretching of symmetry $F_{2 g}$ located at $\sim 520 \mathrm{~cm}^{-1} \cdot{ }^{[26,27]}$ Since its spectrum is formed by only one peak, any changes induced by the sample preparation will be easily detected. The material we used was obtained from the waste dump of the electrometallurgy plant Pechiney in Montricher-Albanne, Haute-Savoie, France.

\section{Quartz}

Quartz $\left(\mathrm{SiO}_{2}\right)$ is the standard mineral used to study the effects of crushing (i.e. sample preparation) on Raman spectra. ${ }^{[23]}$ We used pure quartz (no traces of organic matter) from a hydrothermal vein associated with a gold deposit in granite from Saint-Yrieix-la-Perche, Haute-Vienne, France. The spatial symmetry of quartz ( $\alpha$-quartz) is $\mathrm{D}_{3}^{4}$. Its spectrum consists of several bands corresponding to $\mathrm{A}_{1} \mathrm{Si}-\mathrm{O}$ stretching $\left(1085 \mathrm{~cm}^{-1}\right)$, E Si-O stretching $\left(697 \mathrm{~cm}^{-}\right.$ $\left.{ }^{1}, 795 \mathrm{~cm}^{-1}, 1070 \mathrm{~cm}^{-1}, 1162 \mathrm{~cm}^{-1}\right), \mathrm{A}_{1} \mathrm{O}$-Si-O bending $\left(356 \mathrm{~cm}^{-1}\right)$, E O-Si-O bending (394 $\left.\mathrm{cm}^{-1}, 450 \mathrm{~cm}^{-1}\right), \mathrm{A}_{1} \mathrm{Si}-\mathrm{O}$ stretching/O-Si-O bending $\left(464 \mathrm{~cm}^{-1}\right)$, E O-Si-O bending/Si-O-Si bending $\left(265 \mathrm{~cm}^{-1}\right), \mathrm{A}_{1} \mathrm{Si}-\mathrm{O}$ stretching/O-Si-O bending/Si-O torsion $\left(207 \mathrm{~cm}^{-1}\right)$ and $\mathrm{E}$ O-Si-O bending/Si-O-Si bending/Si-O torsion $\left(128 \mathrm{~cm}^{-1}\right)^{[28]}$. On Earth, quartz is ubiquitous but on Mars it has only recently been detected in the form of amorphous silica associated with hydrothermalism and/or diagenesis. ${ }^{[29}$ This mineral phase is of particular relevance because it was the lithifying phase of ancient terrestrial volcanic sediments (now largely microcrystalline quartz or chert ${ }^{[30]}$ and the fossilising medium of the traces of life contained in the sediments.$^{[31-34]}$ Two samples of the ancient sediments $~ 3.5$ Ga-old terrains in Australia (the Pilbara) and South Africa (Barberton) were included in this study and described below. The relevance of these rocks for Mars is that the silicification of the ancient sediments was induced due to the strong influence of silica-rich hydrothermal fluids on the saturation of silica in the Early Archaean seawaters. ${ }^{[35]}$ This is of relevance to Early Mars because the planet was as volcanically and hydrothermally active as the early Earth and water in impact craters, or the hypothesised northern ocean, may also have been saturated in silica. The presence of silica on Mars may thus indicate ancient hydrothermal activity. ${ }^{[36]}$

\section{Graphite and charcoal}

The graphite used for this study comes from the Alibert mine in the Sayan Mountains, Russia. We used commercial charcoal as representative of biogenic carbon. The first order Raman spectrum of graphite consists of a strong single line (G) at $1582 \mathrm{~cm}^{-1}$ and a smaller band at 42 $\mathrm{cm}^{-1}$ which corresponds to the $\mathrm{E}_{2 \mathrm{~g} 2}$ and $\mathrm{E}_{2 \mathrm{~g} 1}$ vibrational modes respectively. ${ }^{[37,38]}$ For disordered carbon, additional bands appear at $1360 \mathrm{~cm}^{-1}$ (D), $1620 \mathrm{~cm}^{-1}$ (D') and $2960 \mathrm{~cm}^{-1}$ 
(D'). Second order Raman bands are also observed between $2400 \mathrm{~cm}^{-1}$ and $3200 \mathrm{~cm}^{-1}$. The ratio of intensities and the widths of the $D$ and $G$ peaks provide information about the degree of disorder. ${ }^{[39,40]}$ The latter is very small in graphite but larger in the less well-ordered charcoal. Despite this correlation between Raman spectra and the microstructure of carbonaceous matter, ancient organic matter of biological origin in rocks (known as kerogen) is difficult to distinguish from abiogenic carbon using Raman spectroscopy. ${ }^{[7,41]}$ Moreover, high grade metamorphism tends to increase the intensity of peak $\mathrm{G}^{[42]}$ while abrasion can increase the intensity of peak $D .^{[43,44]}$

\section{Rocks}

A number of rock samples was used to examine the effect of crushing on the detection and identification of mineral phases. In some cases, the samples included kerogenous traces of life.

\section{Basalt}

Basalt is the most common rock on Mars. ${ }^{[45]}$ The sample we used was collected from Roca Neyra, Perrier, France ${ }^{[46,47]}$ and is a geochemical and textural analogue of basalts analyzed on Mars. ${ }^{[45,48]}$ Rocks are composites of several minerals and thus do not have a specific characteristic Raman spectrum. Basalts consist of olivine, pyroxene, plagioclase, spinels and accessory minerals (e.g. calcite, apatite, zeolite) in a glassy matrix.

\section{Silicified volcanic sediments (cherts)}

As noted above, the oldest sedimentary rocks on Earth are silicified volcanic sediments (cherts). ${ }^{[30]}$ Here we use two Early Archaean cherts which both contain traces of ancient $\operatorname{life}^{[22,32-34]}$ : the 3.45 Ga-old Kitty's Gap Chert, from Pilbara, Australia, and the 3.3 Ga-old Josefsdal Chert from Barberton Greenstone Belt, South Africa. Volcanic sediments and their alteration products are common on Mars although, to date, silicified volcanic sediments (cherts) have not yet been found. Nevertheless, silica of possible hydrothermal origin has been identified on Mars ${ }^{[36]}$. Given the similarities in the microbial-scale environmental conditions of early Mars and early Earth, primitive life forms on both planets (assuming that life appeared on Mars) were likely to have had similar characteristics and lifestyles. ${ }^{[49]}$ Fossilised traces of pre-Noachian/Noachian (-4,5 to $-3,5 \mathrm{Ga}$ ) life on Mars may therefore be similar in size and shape to the very primitive forms of life that exist as silicified microfossils in the Josefsdal and Kitty's Gap cherts. ${ }^{[22,34]}$ These sediments are therefore particularly relevant for Mars.

\section{Sample preparation}

Bulk samples of the rocks and minerals were analysed. Subsamples of the rocks and minerals were then crushed using an agate mortar and pestle. The crushed samples were sieved into four different grain sizes according to the Wentworth classification system ${ }^{[50]}: 160-100 \mu \mathrm{m}$, 100-63 $\mu \mathrm{m}, 63-40 \mu \mathrm{m}$ and $<40 \mu \mathrm{m}$. The graphite powders tended to flocculate and were therefore washed with deflocculating agent (phosphate-buffered saline solution diluted in $\sim 200 \mathrm{ml}$ of pure water), copiously rinsed and dried. This additional step removed small grains 
which adhered to the lager graphite grains because of electrostatic forces, an effect not observed with the other samples. The samples were prepared for Raman analysis by placing the different grain size powders from individual samples next to each other on a glass slide and pressing the powder flat to decrease the surface roughness.

Powders of the samples in the $200-250 \mu \mathrm{m}$ size range were also produced because this is the size of the crushed materials that will be produced by the ExoMars crusher. ${ }^{[51]}$

\section{Methods}

A WITec Alpha500 RA Raman spectrometer with a green laser $(\lambda=532 \mathrm{~nm}, \mathrm{Nd}$ :YAG frequency doubled laser) was used (CBM, Orléans). The laser is connected to the system via a polarized optical fibre and is focussed on the surface using optical microscope objectives.

Depending on the objective used, the spot size can be relatively small and the laser irradiance on the sample surface, estimated using a calibration grid obtained from the constructor data, can be relatively high (see Table S1). Two gratings were used for the spectrometer: 600 $\mathrm{g} / \mathrm{mm}$, with a spectral range of $\sim 4000 \mathrm{~cm}^{-1}$ and a resolution of $\sim 3 \mathrm{~cm}^{-1}$, as well as a 1800 $\mathrm{g} / \mathrm{mm}$, with a spectral range of $\sim 1300 \mathrm{~cm}^{-1}$ and a resolution of $\sim 1 \mathrm{~cm}^{-1}$. The system was optimized for mapping with a piezo-electric positioning system mounted on a motorized moving stage. The samples were scanned over areas ranging from a few $\mu \mathrm{m}^{2}$ to up to several $\mathrm{cm}^{2}$ and several thousands of spectra were acquired per scan (see Table S1). Large area scans were made of each glass slide. Very small changes in Raman spectra that would have been impossible to detect using single spectra were highlighted on the Raman maps. In this way it was possible to observe the variations in the spectra as a function of grain size. The average spectrum for each grain size range was obtained from these maps.

A laboratory model of the ExoMars RLS device (Fig. S1a), developed at the Associated Unit University of Valladolid-CSIC-Center of Astrobiology (UVa-CAB), was used to study the effect of crushing on in situ measurements on Mars. ${ }^{[9]}$ The laboratory model has an XYZ positioning system with $2.5 \mu \mathrm{m}$ precision and imaging, autofocus, and spectral acquisition capabilities. It can be programmed to work autonomously. ${ }^{[52]}$ The analytical strategy of the RLS instrument is the acquisition of spectra along a linear series of points. At each point, the optical head is focused on the sample, the acquisition parameters (i.e., integration time and number of accumulations) are automatically calculated, and the spectrum acquired. The RLS instrument is equipped with a green laser $(\lambda=532 \mathrm{~nm})$, a spot size of $50 \mu \mathrm{m}$ diameter yielding an irradiance level between 0.6 and $1.2 \mathrm{~kW} / \mathrm{cm}^{2}$, with a $6-7 \mathrm{~cm}^{-1}$ spectral resolution. Raman spectra were also obtained at the UVa-CAB with a Horiba Jobin Yvon iHR320 spectrometer using a Spex ISA Spectrum One Nitrogen refrigerated CCD with a grating of $1200 \mathrm{~g} / \mathrm{mm}$ and a green laser ( $\lambda=532 \mathrm{~nm}$ ). This system was interfaced with the RLS simulator in order to acquire the Stokes and Antistokes signals (Fig. S1b). Analyses with the ExoMars RLS simulator and iHR320 spectrometer were carried out on the same sieved powders as those analysed by the WITec laboratory instrument. The parameters used for the analyses with the RLS simulator and the iHR320 systems are displayed in Table S2 and Table S3, respectively. 


\section{Results}

\section{Minerals}

The Raman spectra of the bulk samples are displayed in Fig. S2.

\section{Silicon}

The Raman maps made with the WITec instrument shown in Fig. 2 demonstrate that the main peak position has shifted from $521 \mathrm{~cm}^{-1}$ to $493 \mathrm{~cm}^{-1}$ with decreasing grain size. This is associated with the observed increase in Full Width at Half Maximum (FWHM), from $6.7 \mathrm{~cm}$ ${ }^{1}$ to $27.7 \mathrm{~cm}^{-1}$, an increase in peak asymmetry (broadening on the left of the peak), as well as an increase in the background level. Moreover, new peaks appear in the spectrum at about 280 $\mathrm{cm}^{-1}$. The RLS simulator documented similar effects on the different size classes but did not observe the appearance of new peaks. Peak displacement and broadening, as well as a decrease in intensity correlate with the reduction of grain size. For the smaller grain size, the peak shifted from $521 \mathrm{~cm}^{-1}$ to $504 \mathrm{~cm}^{-1}$ and the FWHM increased to $8.2 \mathrm{~cm}^{-1}$ with respect to the bulk sample. However, no significant changes were observed in size range of the ExoMars-type powdered sample $(200-250 \mu \mathrm{m})$. Complementary experiments made with the iHR320 system on the sample powder showed that the peak displacement was only about 3 $\mathrm{cm}^{-1}$ and that the broadening was lower than $4.5 \mathrm{~cm}^{-1}$ with respect to the bulk sample. Such variations are within the range of the resolution of the RLS simulator and explain why they were not observed.

\section{Quartz}

In contrast to silicon, the quartz spectrum is not as significantly modified and the variations are small; $\sim 1.4 \mathrm{~cm}^{-1}$ for the shift and $\sim 0.8 \mathrm{~cm}^{-1}$ for the FWHM, as seen in Fig. 3. A peak located at $520 \mathrm{~cm}^{-1}$, not detected in the bulk sample, increases in intensity with decreasing grain size. Finally, the background levels strongly increase with corresponding decrease in grain size. Using the RLS simulator, a very slight displacement of the main peak can be seen in the spectrum of smallest grain size sample with respect to the bulk sample. A very weak peak at $520 \mathrm{~cm}^{-1}$ also appeared. Irrespective of the grain size, an increase of the background level with respect to the bulk sample is observed.

\section{Graphite and charcoal}

The Raman spectra of graphite and charcoal powders obtained using the WITec laboratory instrument and the RLS system are shown in Fig. 4. The G/D intensity ratio remains unchanged and the graphite remains clearly distinguishable from charcoal. However, the signal/noise ratio dramatically decreases with corresponding decrease in grain size as a result of a strong increase in the background level. The charcoal sample was also very sensitive to laser power and burned easily, especially at the smallest grain sizes. Finally, the presence of the D peak in the Raman spectrum of the bulk graphite (Fig. S2c and Fig. 4a,b) can be explained by surface effects induced by the cutting process. ${ }^{[4,44]}$ 


\section{Rocks}

Basalt

Rocks consisting of multiple minerals require the acquisition of several Raman spectra to detect each mineral and, thus, spectral mapping is very useful for detecting all the phases within a sample. The Raman maps in Fig. 5 were made for the polished surface of the rock and powdered rock in different grain size using the WITec system. The Raman map made on the polished rock surface of the bulk sample demonstrates its fine crystalline structure and the large number of mineral phases within a small area. Minerals identified include labradorite (plagioclase), augite (pyroxene), forsterite (olivine) and apatite. Trace amounts of elemental carbon were also detected, as well as an unidentified mineral, possibly spinel.

After crushing, recognition of the different minerals becomes more difficult with decreasing grain size. The background level increases strongly and the empty spaces between the grains diminish the number of spectra per scan. Without any prior knowledge of the studied sample, detection of the different minerals in the scanned areas would be very difficult. Identification of the minerals on the maps was made by a correlation process using the original spectra accumulated on the bulk sample. Even with this technique, not all the minerals observed in the bulk sample could be detected in the Raman maps. The crushing process also leads to the loss of texture and the pattern of mineral distribution can no longer be used for petrological interpretation of the rock. The value of Raman mapping is significantly reduced on powdered material and the best way to study these samples was to make a series of single spectra. A line scan of more than 100 single spectra using autofocus was thus made on the larger grain size powder. With this method, it was possible to detect the major phases, as seen Fig. 5c. However, due to the small spot size $(<1.5 \mu \mathrm{m})$, the probability of detecting minor phases was very low.

The RLS system uses a similar line scan procedure but, due to its larger spot size $(50 \mu \mathrm{m})$, it was capable of detecting more phases with fewer measurements (here 30 single spectra). However, the individual spectra obtained correspond to a mixture of the spectra of a number of minerals, as can be seen in Fig. 5d.

\section{Silicified volcanic sediments (cherts)}

The silicified volcanic sediments samples were first characterized on a cut surface of the rock (similar to the surface of a rock prepared using the Rock Abrasion Tool of the Mars Exploration Rovers) and in thin section preparations of the rock (Fig. 6). Although the rock contains microfossils, these structures are too small to be observed by optical microscopy, even in thin section. However, the black layers of the Josefsdal chert contain detectable intact layers consisting of in situ or detrital fragments of microbial mats and other microbial remains (see Fig. 6d,e). Likewise, in the Kitty's Gap Chert sample carbonaceous remains of microbial colonies can be observed microscopically on the surface of volcanic grains (Fig. 6i,j). The relationship between the texture observed in the optical view and the distribution of the carbonaceous matter detected by Raman spectroscopy is readily apparent in Fig. 6. Although the Raman spectrum of kerogen is not sufficient to demonstrate its biogenicity, the 
distribution of carbon within the rock and its association with particular minerals is sufficient to, at least, locate interesting areas for further, potential biosignature investigation. Once crushed, the powders of the originally black and white laminated rocks are relatively uniform in colour. Raman mapping of the powder revealed only the presence of quartz. On the other hand, the line scan method, similar to that used for the analysis of the basalt, provided several spectra of carbonaceous matter, as well as quartz. However, the spatial relationship of the carbonaceous matter with respect to particular minerals was lost.

The experiments performed with the RLS simulator showed that this instrument was capable of easily detecting the carbonaceous matter in the sample and carbon peaks occurred in almost all the spectra acquired. In addition, all other minerals detected in the bulk rock were found. As for the basalt, this is due to the larger spot size of the RLS simulator compared to that of the WITec instrument. Figure 7 shows a typical Raman spectrum acquired with the RLS simulator compared with the average spectrum of 80 spectra obtained with the WITec system in which ankerite was also observed.

\section{Discussion}

\section{Minerals}

Heating induced during measurement with a Raman laser can be very high, in particular with the WITec system where the spot size is only about $1.5 \mu \mathrm{m}$ in diameter. Thermal effects can thus explain some of the changes observed in the silicon and quartz spectra. The shift and broadening of the main peak of quartz ${ }^{[53]}$ and silicon ${ }^{[54]}$ with temperature is well known. In order to confirm the thermal origin of the observed changes, complementary investigations were made. The evolution of the Raman spectrum of the finest silicon powder with increasing laser power was studied using the WITec system and a broadening and shift in the main peak were observed (Fig. 8a). A series of spectra on the same powder were also acquired with the iHR320 system interfaced with the RLS system (see Fig. S2b). This configuration allows measurement of the intensity ratio between the Stokes and Antistokes signals that is known to be function of the temperature: ${ }^{[55,56]}$

$$
T=\frac{h c \bar{\nu}}{k\left[\ln \frac{I_{S}}{I_{A S}}+4 \ln \left(\frac{1+\lambda \bar{\nu}}{1-\lambda \bar{\nu}}\right)\right]}
$$

where $h$ is the Planck constant, $c$ the speed of light, $k$ the Boltzmann constant, $\bar{v}$ the peak wavenumber, $\lambda$ the laser wavelength, $I_{S}$ the Stokes and $I_{A S}$ the Antistokes peaks intensity. Based on this equation, the evolution of the local temperature with the different grain sizes was plotted in Fig. 8b. The temperature reaches more than $280^{\circ} \mathrm{C}$ for the smaller grain size, despite the very low irradiance used $\left(1.2 \mathrm{~kW} / \mathrm{cm}^{2}\right)$. Peak position with respect to temperature has been previously measured on bulk silicon. ${ }^{[54]}$ For a temperature of $280^{\circ} \mathrm{C}$ it is $\sim 519 \mathrm{~cm}^{-1}$. This is in accordance with the iHR320 measurement of $518 \mathrm{~cm}^{-1}$. Using the same model, the temperatures corresponding to $\sim 504 \mathrm{~cm}^{-1}$, as measured with the RLS system, and to $\sim 493 \mathrm{~cm}^{-}$ 
${ }^{1}$, as measured with the WITec system on the smallest grain size powder, are $760^{\circ} \mathrm{C}$ and $1200^{\circ} \mathrm{C}$ respectively. The strong increase of the temperatures with decreasing grain size can be explained by the fact that small particles cannot evacuate heat as well as large particles, i.e. the thermal conductivity of the material decreases with grain size. This effect is all the more important since silicon is black. Changes in wavenumber and line width with decreasing grain size have been observed previously and were explained by the contribution of surface modes that are increased in finer grain sized powder. ${ }^{[23]}$ However, our experiments clearly demonstrate that the major reason for this change is the local increase of temperature. Despite its black colour, this study shows that the spectrum of carbonaceous matter was not as affected by this strong increase in temperature as suggested by previous studies. ${ }^{[41]}$

Conversely, the appearance of the new peak at $520 \mathrm{~cm}^{-1}$ in the quartz spectrum is not a thermal effect associated with the power of the laser. This peak is characteristic of coesite ${ }^{[57]}$ and corresponds to the symmetric stretching of oxygen in the four-membered $\mathrm{SiO}_{4}$ tetrahedra ${ }^{[58]}$ However, the Raman spectrum of coesite is normally characterised by additional peaks at $204 \mathrm{~cm}^{-1}, 270 \mathrm{~cm}^{-1}, 355 \mathrm{~cm}^{-1}$, and $426 \mathrm{~cm}^{-1}$ which were not present in our sample. ${ }^{[57]}$ A similar situation was previously noted in the quartz spectrum in an eclogite from Antartica ${ }^{[59]}$ In the latter case, it was proposed that the coesite crystalline structure was attained at the nanometric scale within anomalous $\alpha$-quartz (called cryptic coesite), which developed under high pressure. In order for this peak to appear experimentally, quartz must be shocked at several tens of GPa. ${ }^{[60]}$ Since this level of pressure was not reached during the crushing of our samples, we therefore propose that the presence of this peak is related to a surface effect. Indeed, the crushing process may create grains with uncommon surface crystalline orientations leading to particular dangling bonds which have a similar vibrational mode to those of the cryptic coesite. Thus, the probability of observing this peak at $520 \mathrm{~cm}^{-1}$ increases with higher grain density in the crushed samples, which agrees with our observations in this study.

In order to verify this assertion, several Raman analyses were made on the surface of large fragments broken off of the quartz sample. As shown in Fig. 9, the peak at $520 \mathrm{~cm}^{-1}$ was observed in spectra made on the surface of concentric rings of conchoidal fractures. The peak disappears when the analysis is made deeper into the sample. These observations on an uncrushed sample are in accordance with a surface effect.

The appearance of new peaks around $280 \mathrm{~cm}^{-1}$ in the silicon spectrum is explained by the acoustic phonons of representation $\mathrm{A}_{1 \mathrm{~g}}+\mathrm{E}_{\mathrm{g}}+\mathrm{F}_{2 \mathrm{~g}}$ appearing in a certain polarisation configuration (z'(y'y') $\bar{z}$ '). ${ }^{[26,27]}$ This phenomenon is only observable with the WITec system which uses a linearly polarized laser beam, whereas the RLS simulator does not. In powders, grains are randomly oriented and the density of specifically oriented grains increases with decreasing grain size.

Mineral identification using Raman spectroscopy is made by comparing an acquired spectrum with that of reference spectra from the literature or from compiled databases (e.g. RRUFF). Significant changes in the characteristics of Raman spectra, such as those observed in silicon, can lead to serious misidentification of species. Using the spectrum of the smallest grain size 
powder of silicon, comparison with the RRUFF database via the CrystalSleuth software (http://rruff.info/) shows a match of only $14 \%$ with silicon, the best match (93\%) being Paulingite, a rare zeolite mineral with the formula $(\mathrm{K}, \mathrm{Na}, \mathrm{Ca})_{3-4}(\mathrm{Si}, \mathrm{Al})_{21} \mathrm{O}_{42} \cdot 17-22 \mathrm{H}_{2} \mathrm{O}$. This experience underlines the potential problems that may arise by Raman analyses of crushed minerals. ${ }^{[19]}$

Since larger spot sizes of the ExoMars RLS result in lower irradiance, the changes in spectral parameters described above are strongly reduced and many of the thermal effects are negligible or nonexistent, with the exception of the increase in background level. Changes induced by the structure of the powder itself (eg. new peaks, surface effects, etc) are relatively limited and we conclude that the crushing of samples during the future ExoMars mission will not have a necessarily negative effect on identification of the Raman spectra of minerals.

\section{Rocks}

By definition, a rock contains several mineral phases that can sometimes be of very small size, such as the basalt analysed in this study. If the Raman spot size is larger than these phases, the resulting spectrum will correspond to a mixture of the individual spectra of several minerals, as demonstrated by the RLS system with its $50 \mu \mathrm{m}$ spot size. It was shown before that the limit of identification of an unknown material is different from the limit of detection of a known material. ${ }^{[19]}$ Indeed, a single peak is most of the time not sufficient to indentify a material, in particular when mixed with other compounds that may exhibit similar Raman bands. The technical parameters such as the wavelength of the laser, the spot size, the CCD camera, etc. must be carefully chosen in order to improve this identification limit. ${ }^{[19]}$ This assertion is all the more true while working on powdered rocks that are characterised by a mixtures of several compounds. However, we have shown that deconvolution of the different spectra can be facilitated by the acquisition of several tens of spectra at different locations on the sample since the probability of always obtaining exactly the same mixture is very low. Most of the minerals present in the rocks used in this experiment, as well as the carbonaceous matter, were thus detected and indentified with the RLS system. Moreover, due to the mixing of the components in the powder, the probability of detecting minor phases within a sample (including those occurring at down to $1 \%$ of the mass ${ }^{[52]}$ ) is strongly increased. For instance, the RLS system allows detection of carbonaceous matter in the cherts when the probability of detecting it by chance in the bulk sample would have been very low because of its specific distribution. In this case, working on powders is advantageous, except if the detected phase would not be "representative" of the sample (e.g. inclusion, alteration, contamination...).

The most important influence of the crushing process is on the loss of texture, i.e. the spatial relationship between the minerals. Without this textural context, it would be difficult to distinguish between rocks consisted of the same minerals but formed in different contexts (basalts and gabbros for example). This loss of texture will also have consequences on the search for past traces of life. As noted above, Raman spectroscopy cannot distinguish between biotic and abiotic carbon. Only the direct correlation of carbonaceous matter with specific structures and/or minerals in the Josefsdal and Kitty's Gap cherts could indicate a potential 
biosignature. Whereas Raman mapping and optical microscopy on bulk rock allow observation of these very fine details, they are destroyed once the sample has been crushed and, thus, the detection of biosignatures is strongly compromised.

Our study demonstrates that, despite the limitations of the analytical possibilities of the in situ ExoMars RLS system (i.e. only few tens of spectra per sample, no high resolution mapping, etc), this system is well adapted to analysing crushed samples and can efficiently identify even minor phases in a sample. For instance, carbonaceous traces might be more easily detected in powdered samples than on the bulk ones. In combination with the high resolution images of the sample taken by the CLUPI instrument it might be possible to locate it or infer its mineralogical association. The possibility of preparing polished sections of rocks in situ during a mission would make Raman mapping on such samples very useful, in particular if associated with optical observations made by a close-up imager or a high resolution camera. Finally, classical analysis combining images of texture and spectral data on a bulk sample in their relative context is preferable when working with laboratory systems.

\section{Conclusion and perspectives}

The crushing of minerals may induce changes in Raman spectra in comparison to spectra generated from analyses made on bulk samples. A general increase of the background level, shift in peak position, an increase in peak width, and the appearance of new peaks was observed, depending on the material analysed. These effects are induced by a local increase in heat and by the enhancement of crystallographic surface orientation interactions. Due to the relatively large spot size of the ExoMars RLS system, most of these observed spectral changes for powders analysed are negligible or nonexistent. Sample preparation (i.e. crushing) causes a loss of texture unfavourable and potentially destructive of fine scale features within rocks including any potential traces of life. Thus, detailed optical observations of samples prior to crushing will be essential in order to ensure acceptable interpretations of data generated by RLS and the other instruments of the Pasteur payload. This study demonstrates that the ExoMars RLS system is suitable for analysing crushed samples and is capable of detecting many phases with only few acquisitions. Furthermore, current work at UVa-CAB demonstrates that the limit of detection is enhanced and that semi-quantification could be possible using powdered samples, thus ensuring the best possible scientific return from the RLS instrument in situ on Mars.

\section{Acknowledgements}

We acknowledge the reviewers and Liane Loiselle for their very useful comments which contributed to the development of this paper. We thank Pr. E. Marcoux and M. Bellanger for the provision of graphite and silicon samples respectively. 


\section{References}

[1] H. G. M. Edwards, S. E. Jorge-Villar, J. L. Bishop, M. Bloomfield, J. Raman Spectrosc. $2004 ; 35,458$.

[2] A. Wang, L. A. Haskin, T. J. Wdowiak, S. W. Squyres, R. J. Wilson, L. E. Hovland, K. S. Manatt, N. Raouf, C. D. Smith, J. Geophys. Res. 2003 ; 108E1, 5005.

[3] A. Wang, K. E. Kübler, B. L. Jolliff, L. A. Haskin, Am. Mineral. 2004 ; 89, 665.

[4] N. Tarcea, M. Harz, P. Rösch, T. Frosch, M. Schmitt, H. Thiele, R. Hochleitner, J. Popp, Spectrochim. Acta, Part A 2007 ; 68, 1029.

[5] J. J. Freeman, A. Wang, K. E. Kübler, B. L. Jolliff, L. A. Haskin, Can. Mineral. 2008 ; 46, 1477.

[6] J. Jehlicka, H. G. M. Edwards, P. Vitek, Planet. Space Sci. 2009 ; 57, 606.

[7] C. P. Marshall, H. G. M. Edwards, J. Jehlicka, Astrobiology 2010 ; 10, 229.

[8] ESA ExoMars website - http://www.esa.int/SPECIALS/ExoMars/SEM10VLPQ5F_0.html

[9] F. Rull, S. Maurice, E. Diaz, C. Tato, A. Pacros, RLS Team, Abstr. $42^{\text {nd }}$ Lunar and Planetary Science Conference $2011 ; 2400$.

[10] F. Rull, G. López, A. Catalá, J. Medina, A. Sansano, A. Sanz, F. Sobrón, Abstr. The International Conference: Exploring Mars Habitability, Lisbon, Portugal, June 13-15 2012.

[11] J.-L. Josset, F. Westall, B.A. Hofmann, J.G. Spray, C. Cockell, S. Kempe, A.D. Griffiths, M.C. De Sanctis, L. Colangeli, D. Koschny, D. Pullan, K. Föllmi, L. Diamond, M. Josset, E. Javaux, F. Esposito, D. Barnes, Geophys. Res. Abstr. 2012 ; 14, 13616.

[12] S. Andò, P. Vignola, E. Garzanti, Rend. Fis. Acc. Lincei 2011 ; 22, 327.

[13] E. Garzanti, S. Andò, C. France-Lanord, P. Censi, P. Vignola, V. Galy, M. Lupker, Earth Planet. Sci. Lett. 2011 ; 302, 107.

[14] R. E. Summons, J. P. Amend, D. Bish, R. Buick, G. D. Cody, D. J. Des Marais, G. Dromart, J. L. Eigenbrode, A. H. Knoll, D. Y. Sumner, Astrobiology 2011 ; 11, 157.

[15] A. Steele, F. M. McCubbin, M. Fries, L. Kater, N. Z. Boctor, M. L. Fogel, P. G. Conrad, M. Glamoclija, M. Spencer, A. L. Morrow, M. R. Hammond, R. N. Zare, E. P. Vicenzi, S. Siljeström, R. Bowden, C. D. K. Herd, B. O. Mysen, S. B. Shirey, H. E. F. Amundsen, A. H. Treiman, E. S. Bullock, A. J. T. Jull, Sciencexpress $2012 ; 10,1120$.

[16] J. Jehlicka, H. G. M. Edwards, Org. Geochem. 2008 ; 39, 371.

[17] A. Culka, J. Jehlicka, P. Vandenabeele, H. G. M. Edwards, Spectrochim. Acta, Part A $2011 ; 80,8$. 
[18] A. Culka, J. Jehlicka, L. Strnad, Spectrochim. Acta, Part A 2012 ; 86, 347.

[19] P. Vandenabeele, J. Jehlicka, P. Vitek, H. G. M. Edwards, Planet. Space Sci. 2012 ; 62, 48.

[20] U. Villanueva, J. C. Raposo, K. Castro, A. de Diego, G. Arana, J. M. Madariaga, J. Raman Spectrosc. 2008 ; 39, 1195.

[21] F. Foucher, F. Westall, in Micro-Raman Spectroscopy and Luminescence Studies in the Earth and Planetary Science, (Eds: A. Gucsik), American Institute of Physics, 2009 ; CP 1163, pp. 47-58.

[22] F. Westall, F. Foucher, B. Cavalazzi, S. T. de Vries, W. Nijman, V. Pearson, J. Watson, A. Verchovsky, I. Wright, J.-N. Rouzaud, D. Marchesini, S. Anne, Planet. Space Sci. 2011 ; $59,1093$.

[23] S. K. Sharma, C. H. Chio, P. Deb, P. G. Lucey, N. Domergue-Schmidt, K. A. Horton,

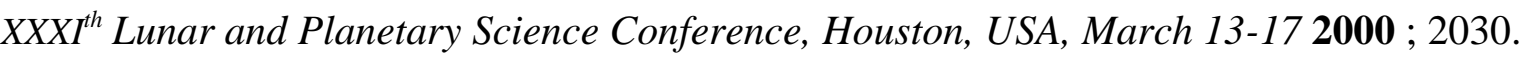

[24] M. E. Back, J. A. Mandarino, Fleischer's Glossary of Mineral Species 2008, The Mineralogical Record Inc., Tucson, 2008, p. 213.

[25] J. L. Jambor, J. Puziewicz, Am. Mineral. 1991 ; 76, 665.

[26] P. A. Temple, C. E. Hathaway, Phys. Rev. B 1973 ; 7, 3685.

[27] R. Poilblanc, F. Crasnier, Spectroscopies infrarouge et Raman, EDP Sciences, Grenoble, 2006, pp. 466-470.

[28] J. Etchepare, M. Merian, L. Smetankine, J. Chem. Phys. 1974 ; 60, 1531.

[29] M. R. Smith, J. L. Bandfield, J. Geophys. Res. 2012 ; 117, E06007.

[30] A. P. Nutman, S. J. Mojzsis, C. R. L. Friend, Geochim. Cosmochim. Acta 1997 ; 61, 2475 .

[31] F. Westall, M. J. de Wit, J. Dann, S. van der Gaast, C. E. J de Ronde, D. Gerneke, Precambrian Res. 2001 ; 106, 93.

[32] F. Westall, C. E. J. de Ronde, G. Southam, N. Grassineau, M. Colas, M., C. Cockell, H. Lammer, Philos. Trans. R. Soc., B 2006 ; 361, 18570.

[33] F. Westall, S. T. de Vries, W. Nijman, V. Rouchon, B. Orberger, V. Pearson, J. Watson, A. Verchovsky, I. Wright, J.-N. Rouzaud, D. Marchesini, A. Severine, Spec. Pap. - Geol. Soc. Am. 2006 ; 405, 105.

[34] F. Westall, B. Cavalazzi, L. Lemelle, Y. Marrocchi, J.-N. Rouzaud, A. Simionovici, M. Salomé, S. Mostefaoui, C. Andreazza, F. Foucher, J. Toporski, A. Jauss, V. Thiel, G. Southam, L. MacLean, S. Wirick, A. Hofmann, A. Meibom, F. Robert, C. Defarge, Earth Planet. Sci. Lett. 2011 ; 310, 468. 
[35] A. Hofmann, R. Bolhar, Astrobiology 2007 ; 7, 355.

[36] S. W. Squyres, R. E. Arvidson, S. Ruff, R. Gellert, R. V. Morris, D. W. Ming, L. Crumpler, J. Farmer, D. J. des Marais, A. Yen, S. M. McLennan, W. Calvin, J. F. Bell III, B.

[37] F. Tuinstra, J. L. Koenig, J. Chem. Phys. 1970 ; 53, 1126.

[38] J. Jehlicka, C. Bény, J. Mol. Struct. 1999 ; 480-481, 541.

[39] C. Bény-Bassez, J.-N. Rouzaud, Scanning Electron Microsc. 1985 ; 1, 119.

[40] E. Quirico, G. Montagnac, J.-N. Rouzaud, L. Bonal, M. Bourot-Denise, S. Duber, B. Reynard, Earth Planet. Sci. Lett. 2009 ; 287, 185.

[41] J. D. Pasteris, B. Wopenka, Astrobiology 2003 ; 3, 727.

[42] O. Beyssac, B. Goffé, C. Chopin, J.-N. Rouzaud, J. Metamorph. Geol. 2002 ; 20, 859.

[43] M. R. Ammar, J.-N. Rouzaud, J. Raman Spectrosc. 2011 ; 42, 5.

[44] O. A. Maslova, M. R. Ammar, G. Guimbretière, J.-N. Rouzaud, P. Simon, Phys. Rev. B $2012 ; 86,134205-(5)$.

[45] H. Y. Mc Sween, G. J. Taylor, M. B. Wyatt, Science 2009 ; 324, 736.

[46] J.-F. Pastre, A. Chambaudet, J. Couthures, C. R. Séances Acad. Sci., Vie Acad. 1983 ; $296,79$.

[47] J.-F. Pastre, Quaternaire $2004 ; 15,87$.

[48] H. Y. McSween, R. E. Arvidson, J. F. Bell III, D. Blaney, N. A. Cabrol, P. R. Christensen, B. C. Clark, J. A. Crisp, L. S. Crumpler, D. J. Des Marais, J. D. Farmer, R. Gellert, A. Ghosh, S. Gorevan, T. Graff, J. Grant, L. A. Haskin, K. E. Herkenhoff, J. R. Johnson, B. L. Jolliff, G. Klingelhoefer, A. T. Knudson, S. McLennan, K. A. Milam, J. E. Moersch, R. V. Morris, R. Rieder, S. W. Ruff, P. A. de Souza, S. W. Squyres, H. Wänke, A. Wang, M. B. Wyatt, A. Yen, J. Zipfel, Science 2004 ; 305, 842.

[49] F. Westall, Science 2005 ; 308, 366.

[50] C. K. Wentworth, J. Geology $1922 ; 30,377$.

[51] A. Sansano, G. Lopez, J. Medina, F. Rull, AMASE 10 team, Abstr. EPSC-DPS 2011 ; 6, 856.

[52] G. Lopez-Reyes, F. Rull, A. Sanz, J. Medina, A. Catala, I. Hermosilla, B. Lafuente, Abstr. GEORAMAN X, Nancy, France, June 11-13, 2012.

[53] T. M. K. Nedungadi, Proc. - Indian Acad. Sci., Math. Sci. 1940 ; 11-2, 86.

[54] T. R. Hart, R. L. Aggarwal, B. Lax, Phys. Rev. B 1970 ; 1, 638. 
[55] D. A. Long, Raman Spectroscopy, McGraw-Hill, New York, 1976, p. 84.

[56] R. Poilblanc, F. Crasnier, Spectroscopies infrarouge et Raman, EDP Sciences, Grenoble, 2006, p. 319.

[57] T. Kobayashi, T. Hirajima, Y. Hiroi, M. Svojtka, J. Min. Pet. Sci. 2008 ; 103, 105.

[58] S. K. Sharma, B. Simons, H. S. Yoder, Am. Mineral. 1983 ; 68, 1113.

[59] R. Palmeri, M. L. Frezzotti, G. Godard, R. J. Davies, J. Metamorph. Geol. 2009 ; 27, 685 .

[60] T. de Rességuier, P. Berterretche, M. Hallouin, J. Appl. Phys. 2003 ; 93, 2123.

\section{Figures captions}

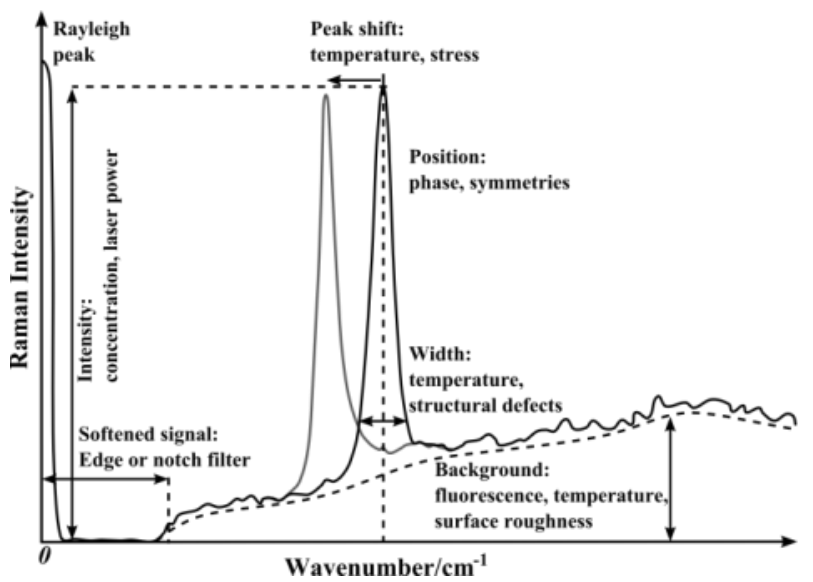

Figure 1. (Illustrative) Annotated Raman spectrum demonstrating the causality of potential modification effects. 

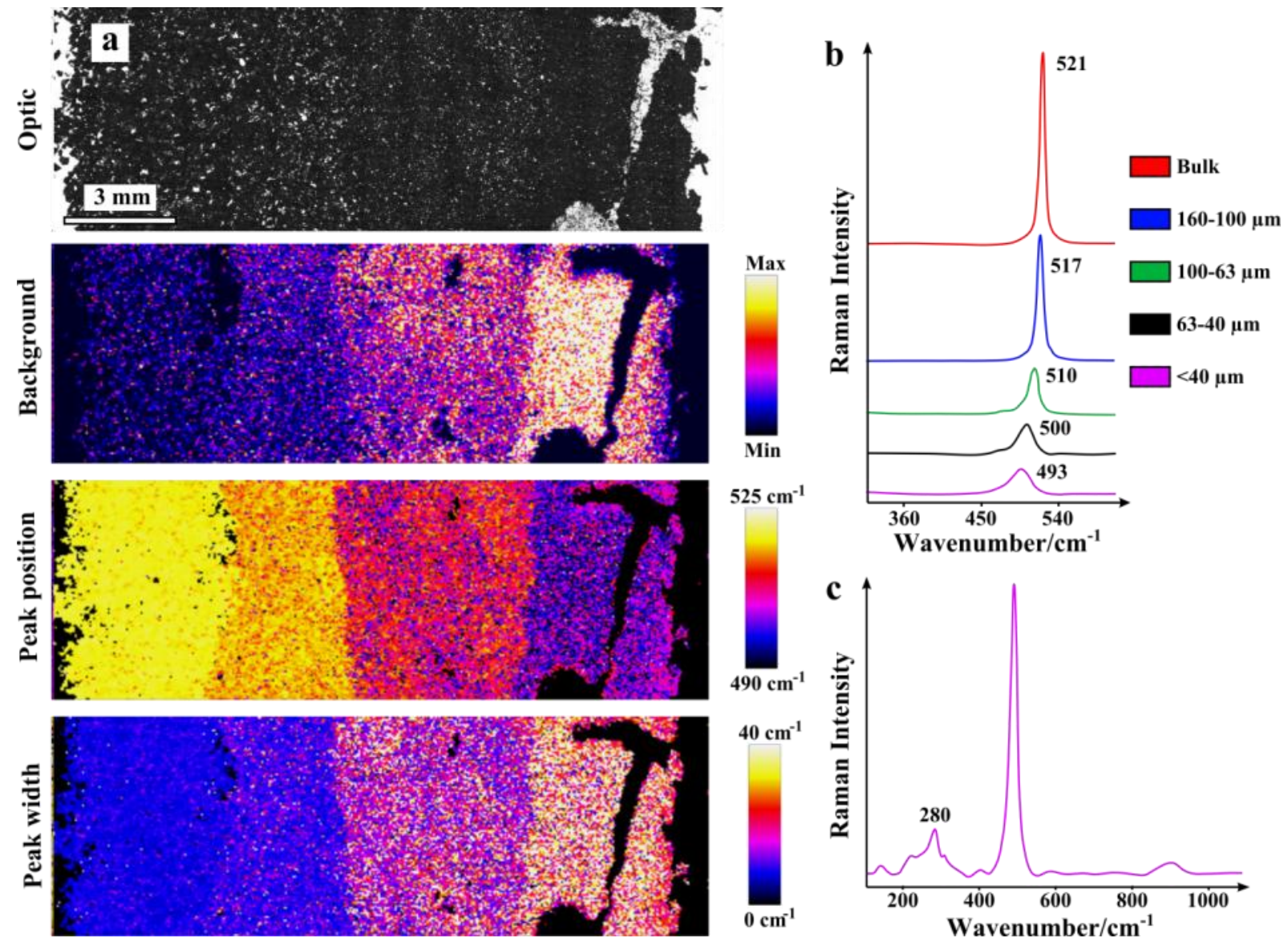

Figure 2. Raman analyses of silicon powders. (a) Photography and large area Raman maps (decreasing in grain size from left to right) showing background level, position of the main peak, and width of the main peak. (b) Average Raman spectra of the main peak for the bulk sample and for each powder. (c) Detailed spectrum of $<40 \mu \mathrm{m}$ grain size powder highlighting the bands in the $280 \mathrm{~cm}^{-1}$ region.

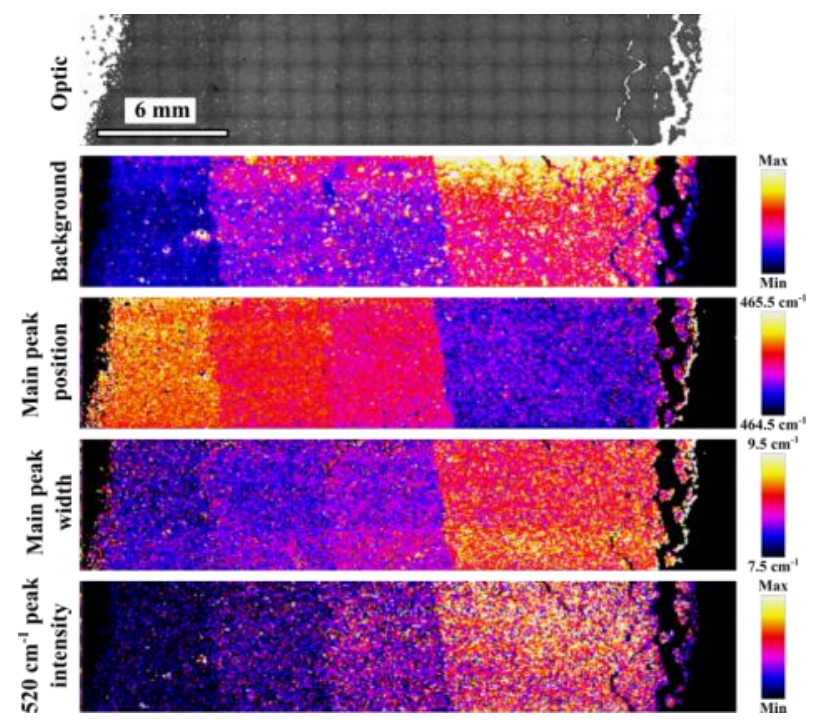

Figure 3. Raman analyses of quartz powders. (a) Photography and large area Raman maps (decreasing in grain size from left to right) showing background level, position of the main peak, width of the main peak and intensity of the peak at $520 \mathrm{~cm}^{-1}$. 


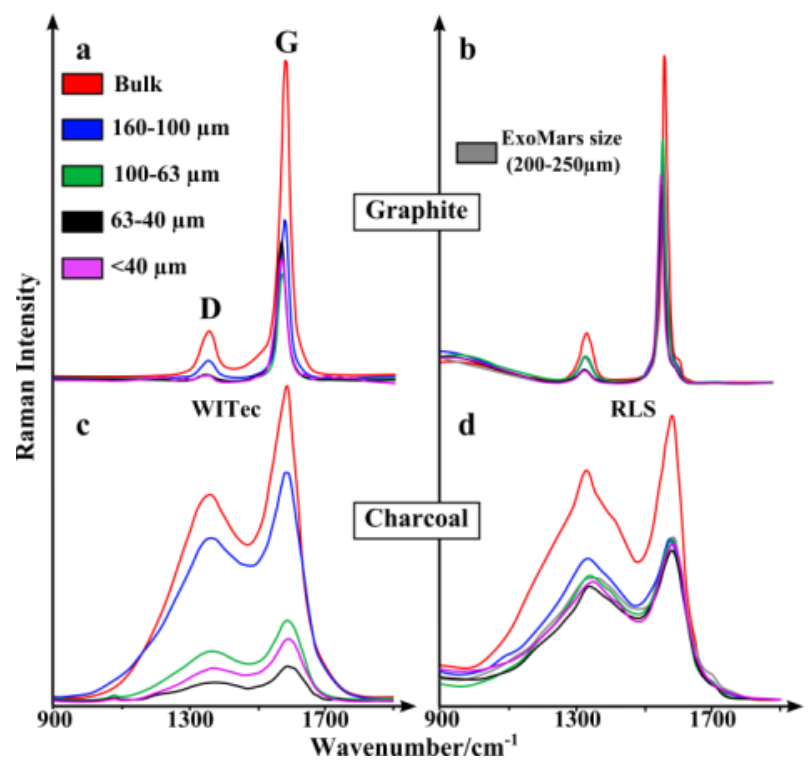

Figure 4. Raman analyses of various graphite and charcoal powders, using with the WITec system (a and c respectively) and the RLS simulator ( $b$ and d respectively) 2.
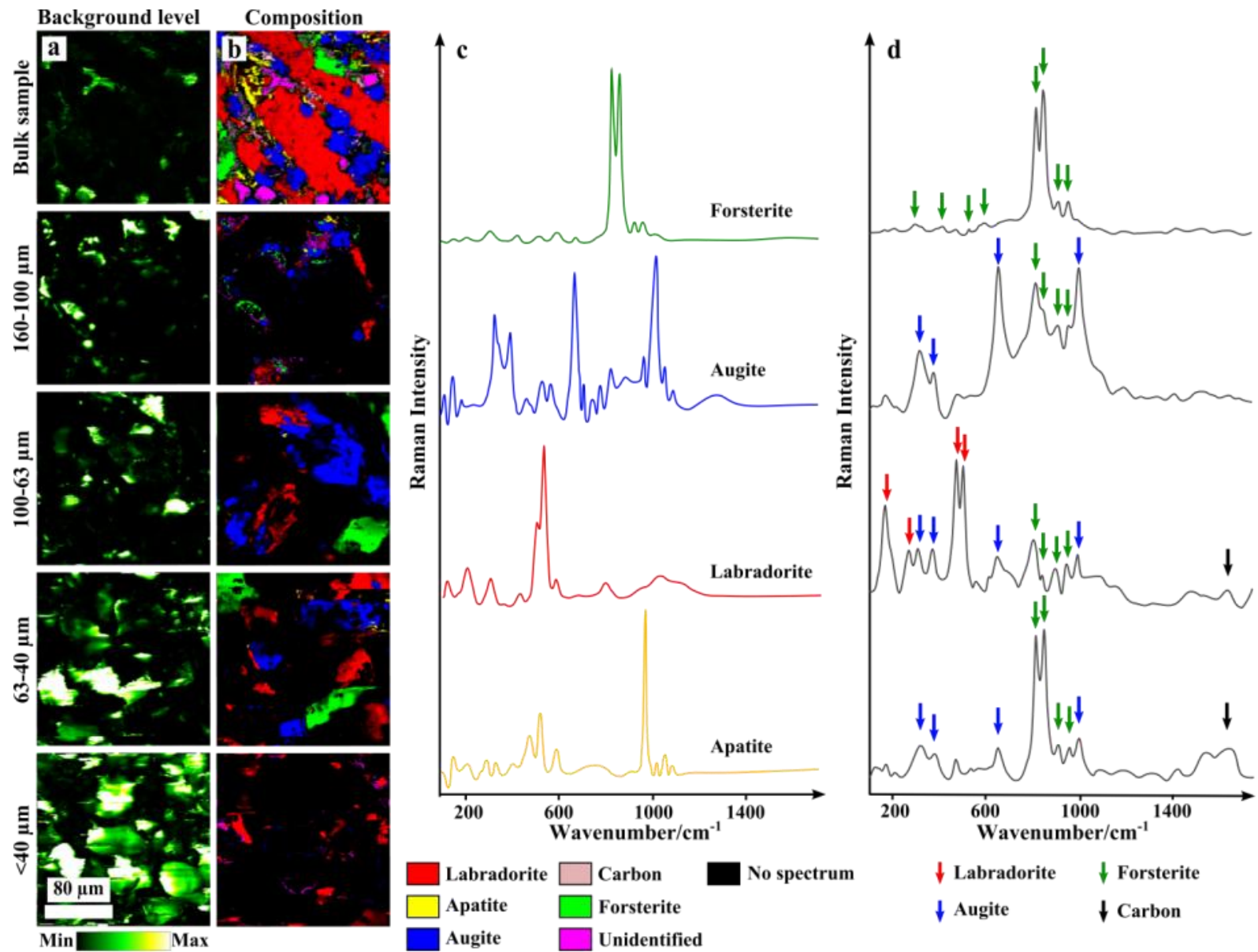

Figure 5. Background level (a) and compositional Raman maps (b) of bulk and powdered basalt samples (scan size 200x200 $\mu^{2}$ ) acquired using the WITec system. Single Raman spectra of 160 to $100 \mu \mathrm{m}$ grain sized basalt powder (c) collected using the line scan method 
with the WITec system, autofocus on. Single Raman spectra of 200-250 $\mu \mathrm{m}$ grain size (ExoMars type) basalt powder (d), collected with the RLS simulator.
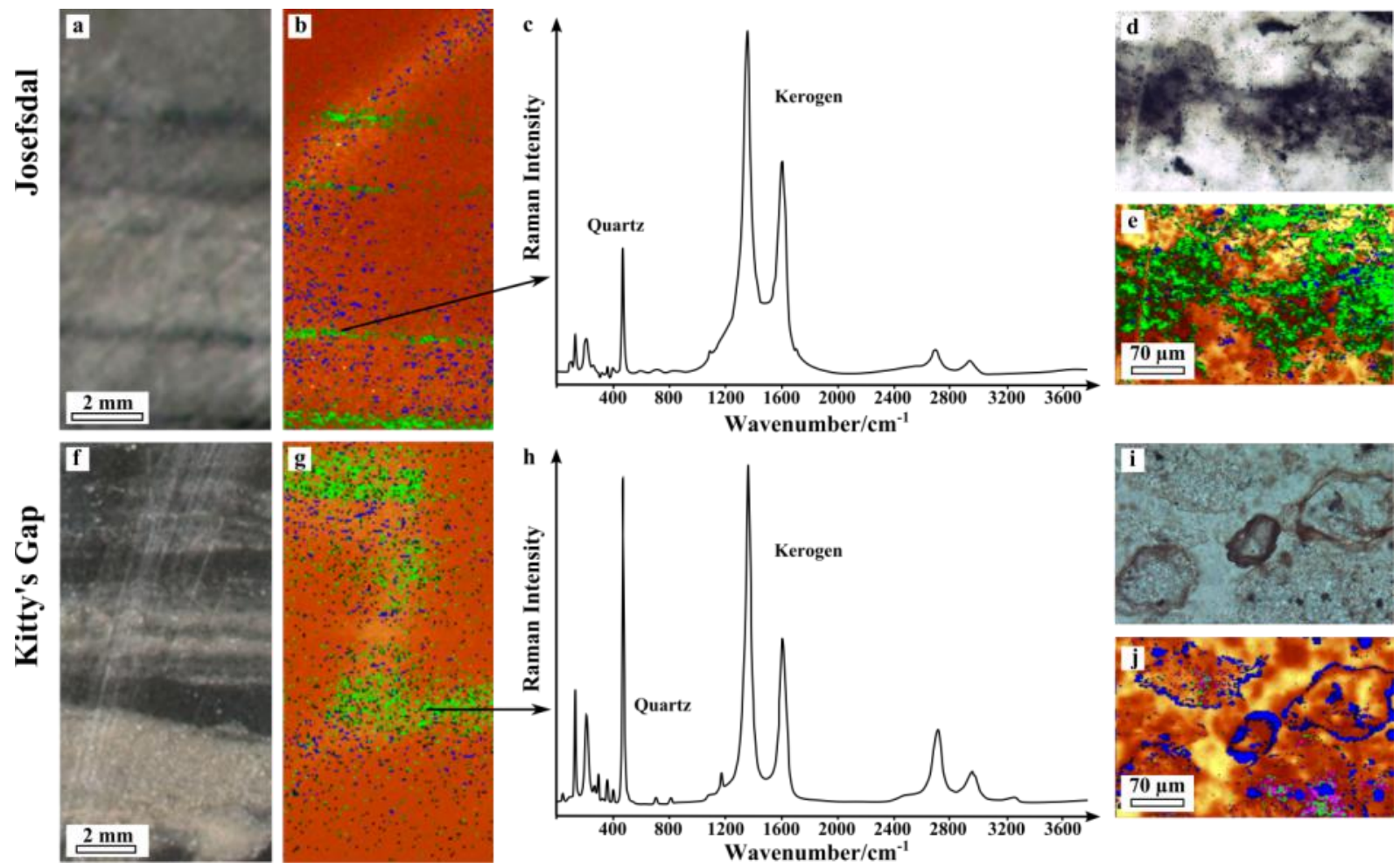

Figure 6. Chert samples from (a-e) Josefsdal, Barberton Greenstone Belt, South Africa, and (f-j) Kitty's Gap, Pilbara, Australia. (a,f) Photography of the cut and polished surfaces and (b,g) corresponding Raman maps, where carbonaceous matter (kerogen) appears green, anatase $\left(\mathrm{TiO}_{2}\right)$ blue and quartz orange. These Raman maps allow rapid detection of areas of interest which can be targeted for further analyses with higher resolution spectral $(\mathrm{c}, \mathrm{h})$ and imaging (optical $(\mathrm{d}, \mathrm{i})$ and Raman $(\mathrm{e}, \mathrm{j}))$ techniques.

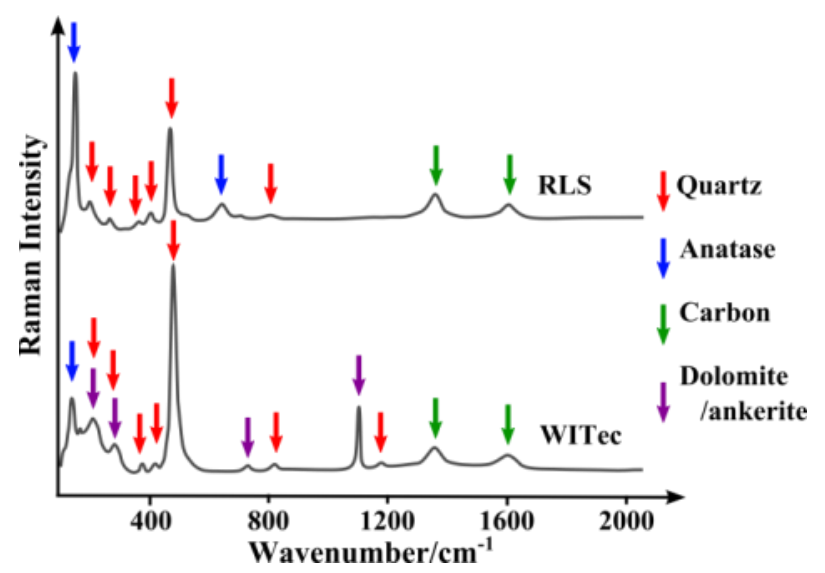

Figure 7. Raman spectra of silicified volcanic sediments powders from Josefsdal, Barberton, South Africa. (a) Typical single spectrum obtained with the RLS instrument and (b) "equivalent" spectrum obtained by averaging 80 spectra acquired with the WITec system. 


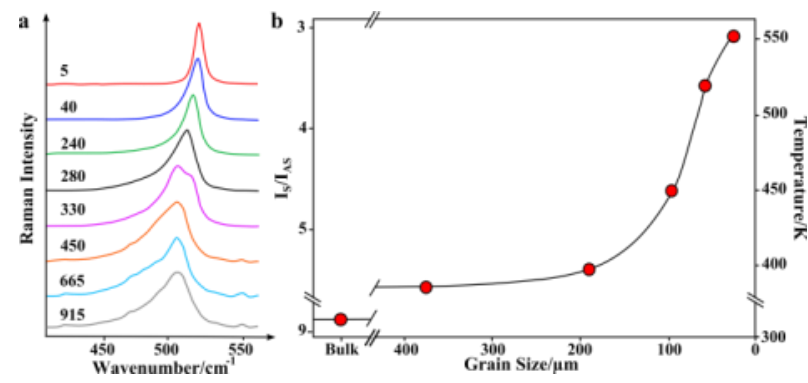

Figure 8. (a) Main peak of silicon corresponding to different laser powers (in $\mathrm{kW} / \mathrm{cm}^{2}$ ) acquired using the WITec system on the $<40 \mu \mathrm{m}$ grain size powder. (b) Stokes and AntiStokes intensity ratio and associated local temperature with respect to the grain size distribution of the silicon sample measured using the iHR320 system interfaced with the RLS simulator.
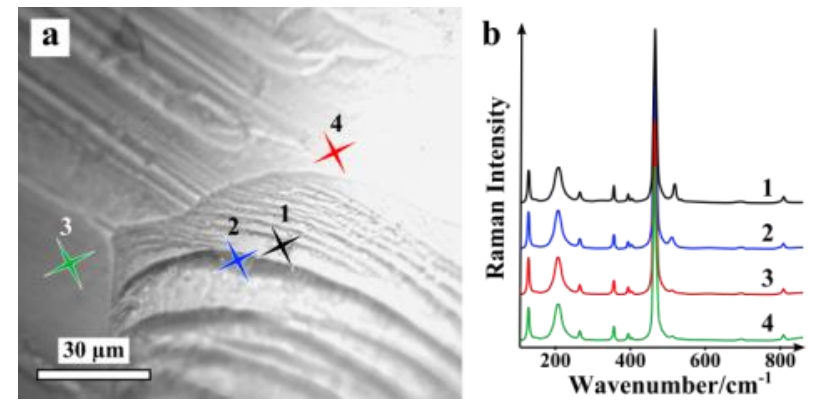

Figure 9. (a) Optical micrograph and (b) associated Raman spectra of a fracture at the surface of the quartz sample.

\section{Supplementary materials}

\section{Figures captions}

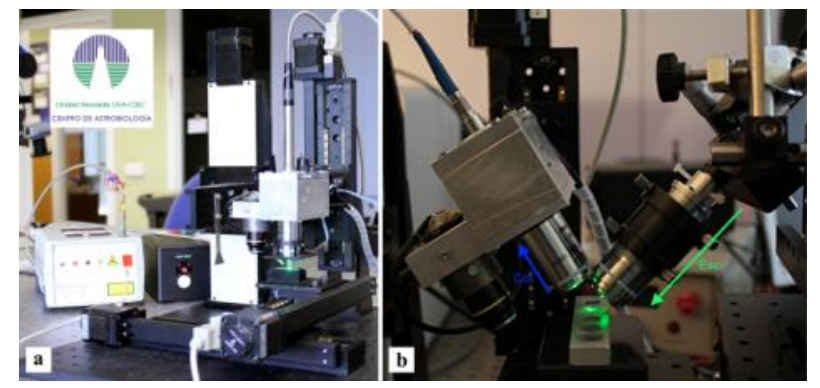

Figure S1. (a) The RLS simulator developed at the Associated Unit University of ValladolidCSIC-Center of Astrobiology (UVa-CAB). (b) Experimental setup used for the acquisition of the Stokes and Anti-Stokes signals. 


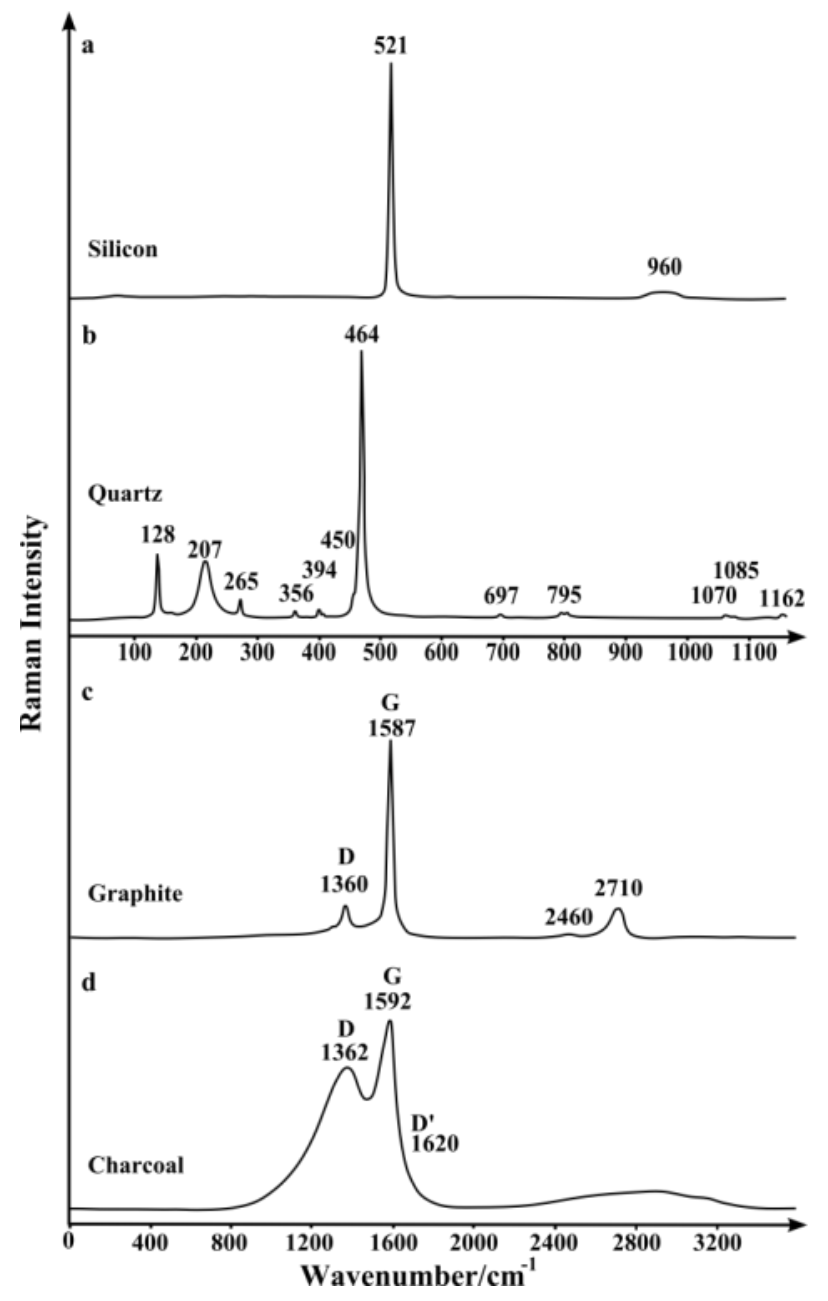

Figure S2. Raman spectra of bulk samples of (a) silicon, (b) quartz, (c) graphite and (d) charcoal.

\section{Tables captions}




\begin{tabular}{|c|c|c|c|c|c|c|}
\hline $\begin{array}{l}\text { WITec Alpha500 RA } \\
\text { Single spectra }\end{array}$ & & & & & & \\
\hline Sample & Number of accmm nlations & Integration time (s) & ObJective and spot size (nm) & Irradiance $\left(\mathbf{k W / c m}{ }^{2}\right)$ & Ascociated ngme & \\
\hline $\begin{array}{l}\text { Basalt powders (Fpectra from } \\
\text { line sean of } 100 \text { speetra and } 200 \\
\mu \mathrm{m})\end{array}$ & 2 & 1 & $20 \times(1623)$ & 1389 & se & \\
\hline $\begin{array}{l}\text { Bulk carbonaccous silicified } \\
\text { voleamic sand (Josefsdal) }\end{array}$ & 3 & 10 & $50 \times(865)$ & 1273 & 6 & \\
\hline $\begin{array}{l}\text { Bullk silicified volcanic sand } \\
\text { (Kitty's ( Oap) }\end{array}$ & 3 & 10 & $50 \times(865)$ & 1273 & $6 \mathrm{~h}$ & \\
\hline Bulk quartz fracture & 5 & 10 & $50 \times(865)$ & 3081 & 9 & \\
\hline Bulls silicon & 3 & 10 & $50 \times(865)$ & 3081 & $\$ 2 \mathrm{a}$ & \\
\hline Bulkquartz & 3 & 10 & $50 \times(865)$ & 3081 & $s 2 b$ & \\
\hline Average spectra & & & & & & \\
\hline Sample & Scan size $\left(\mu \mathrm{m}^{2}\right)$ & Scan resolution (spectra) & Integration tme/spectrum (s) & ObJective & Irradiance (kW/cm²) & Associated ngme \\
\hline Bull graphite & $150 \times 150$ & $50 x 50$ & 0,4 & $20 \times(1623)$ & 913 & $S 2 c$ and $4 a$ \\
\hline Bull charcoal & $150 \times 150$ & $150 \times 150$ & 0,4 & $20 \mathrm{x}(1623)$ & 243 & $\$ 2 \mathrm{~d}$ and $4 \mathrm{c}$ \\
\hline Graphite pouxders & $150 \times 150$ & $50 \times 50$ & 0,4 & $20 \times(1623)$ & 913 & $4 a$ \\
\hline Charcoal pouxders & $100 \times 100$ & $100 \times 100$ & 0,4 & $20 \times(1623)$ & 243 & $4 \varepsilon$ \\
\hline Powdered, carbonacoous & & & & & & \\
\hline $\begin{array}{l}\text { silicified volcamic sand } \\
\text { (Josefsdal) }\end{array}$ & line scan of $800 \mu \mathrm{mm}$ & 80 & $2 \times 5$ & $50 \times(865)$ & 3081 & 7 \\
\hline Silican powder $40-63 \mu \mathrm{m}$ & $100 \times 100$ & $20 \times 20$ & 1 & $20 \times(1623)$ & Various & $8 \mathrm{a}$ \\
\hline Maps & & & & & & \\
\hline Sample & Scan size $\left(\mu^{2}{ }^{2}\right)$ & Scan resolution (spectra) & Integration tme/spectrum (s) & Objective & Irradiance (kW/om²) & Associated ngme \\
\hline Silican powders & $18000 \times 6000$ & $360 \times 120$ & 1,2 & $20 \mathrm{~s}(1623)$ & 365 & $2 \mathrm{a}$ \\
\hline Quartz powders & $30000 \times 6000$ & $400 \times 80$ & 1,7 & $20 \times(1623)$ & 365 & 3 \\
\hline Bulk basalt & $200 \times 200$ & $200 \times 200$ & 0,06 & $20 \mathrm{x}(1623)$ & 1389 & $s_{a, b}$ \\
\hline Basalt powders & $200 \times 200$ & $200 \times 200$ & 0,06 & $20 \times(1623)$ & 1389 & $5 \mathrm{a}, \mathrm{b}$ \\
\hline $\begin{array}{l}\text { Bulle carbonacsous silicified } \\
\text { voleamic sad (Josefsdal) }\end{array}$ & $5000 \times 10000$ & $100 \times 200$ & 0,15 & $20 \times(1623)$ & 365 & $6 \mathrm{~b}$ \\
\hline Thin sertion (Josefslal) & $370 \times 240$ & $185 \times 120$ & 0.3 & $100 \times(721)$ & 1970 & $6 \mathrm{~d}$ \\
\hline $\begin{array}{l}\text { Bulle silicifiod volcanic sand } \\
\text { (Kitty's Gap) }\end{array}$ & $10000 \times 20000$ & $100 \times 200$ & 0,35 & $20 \times(1623)$ & 365 & $\sigma_{g}$ \\
\hline Thin section (Kitty's $G_{a p}$ ) & $370 \times 240$ & $185 \times 120$ & 0.3 & $100 \times(721)$ & 1970 & $G_{\mathrm{i}}$ \\
\hline
\end{tabular}

Table S1. Parameters used for data acquisition with the WITec Alpha500 RA system.

ExoMars RLS simulator

\begin{tabular}{|c|c|c|c|c|c|}
\hline Sample & Number of accumulations & Integration time $(\mathrm{s})$ & Number of points & Irradiance $\left(\mathrm{kW} / \mathrm{cm}^{2}\right)$ & Associated figure \\
\hline Graphite Bulk and Powders & 3 & 20 & 5 & 1 & $4 \mathrm{~b}$ \\
\hline Powdered basalt & \multicolumn{2}{|c|}{ Variable with point } & 30 & 1.2 & $5 d$ \\
\hline Powdered carbonaceous & \multirow{2}{*}{\multicolumn{2}{|c|}{ Variable with point }} & & & \\
\hline $\begin{array}{l}\text { silicified volcanic sand } \\
\text { (Josefsdal) }\end{array}$ & & & 30 & 1.2 & 7 \\
\hline
\end{tabular}

Table S2. Parameters used for data acquisition with the ExoMars RLS simulator system.

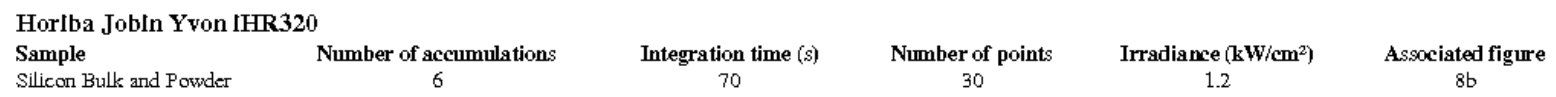

Table S3. Parameters used for data acquisition with the Horiba Jobin Yvon iHR320 system. 